\title{
Standardized Finger-Nose Test Validity for Coordination Assessment in an Ataxic Disorder
}

\author{
Cynthia Gagnon, Jean Mathieu, Johanne Desrosiers
}

\begin{abstract}
Objectives: Evaluation of coordination with the Finger-Nose Test is an essential part of the neurological examination. This study explored the convergent and discriminant construct validity of the Standardized Finger-Nose Test (SFNT) in a neuromuscular disorder with ataxic features. Method: A cross-sectional study was carried out with 24 participants with recessive spastic ataxia of CharlevoixSaguenay. Convergent construct validity was tested by correlating the SFNTwith other upper extremity function tests, a functional independence measure and social participation. Upper extremity function tests included gross and fine dexterity (Box and Block Test and Purdue Pegboard), upper extremity strength (dynamometry) and global upper extremity performance (TEMPA). The Functional Independence Measure (FIM) and the Assessment of Life Habits scale (LIFE-H) measured functional independence and social participation respectively. Discriminant construct validity was explored by comparing performance on the SFNT between two age groups ( $<40$ years and $\geq 40$ years). Results: Convergent validity of the SFNT was demonstrated by moderate to strong correlations with gross and fine finger dexterity $(\mathrm{r}=0.82-0.84)$, global upper extremity performance $(0.74-0.79)$, functional independence $(r=0.74)$ and social participation $(r=0.78)$. Upper extremity coordination of the older group was significantly lower than in the younger group, suggesting the ability of the SFNT to discriminate between different levels of function. Conclusion: This study demonstrated the convergent and discriminant construct validity of the SFNT in a neuromuscular disorder with ataxic features.
\end{abstract}

RÉSUMÉ: Objectifs: L'évaluation de la coordination avec le test doigt-nez est un élément essentiel de l'examen neurologique. Cette étude explore la validité de construit convergent et discriminant du Test Doigt-Nez Standardisé (TDNS) auprès d'une clientèle neuromusculaire présentant des symptômes ataxiques. Méthode: Une étude tranversale a été réalisée auprès de 24 personnes atteintes d'Ataxie récessive spastique de Charlevoix-Saguenay. La validité de construit convergent a été étudiée en explorant les relations entre le TDNS et les fonctions motrices des membres supérieurs, l'indépendance fonctionnelle et la participation sociale. Les fonctions motrices des membres supérieurs incluent la dextérité grossière et fine (Box and Block Test et Purdue Pegboard), la force aux membres supérieurs (dynamométrie) et la performance globale (TEMPA). L'indépendance fonctionnelle et la participation sociale ont été respectivement évaluées avec la Mesure de l'indépendance fonctionnelle (MIF) et la Mesure des habitudes de vie (MHAVIE). La validité discriminante a été déterminée en comparant les scores au TDNS entre deux groupes d'âge ( $<40$ ans et $\geq 40$ ans). Résultats: La validité convergente a été démontrée par des corrélations modérées à élevées entre le TDNS et la dextérité grossière $(r=0,84)$ et fine $(r=0,82)$, la performance globale des membres supérieurs $(r=0,74-0,79)$, l'indépendance fonctionnelle $(r=0,74)$ et la participation sociale $(r=0,78)$. La coordination motrice du groupe des plus de 40 ans est significativement plus faible que celui des plus jeunes suggérant la capacité du TDNS à discriminer des niveaux différents d'atteintes. Conclusion: Cette étude a démontré la validité de construit convergent et discriminant du TDNS auprès de la clientèle neuromusculaire présentant des symptômes ataxiques.

Can. J. Neurol. Sci. 2004; 31: 484-489

Upper limb motor function, including the presence of motor incoordination, is routinely assessed as part of the neurological examination. The clinician relies on it as one of the preliminary diagnostic procedures. It can also be helpful in case management planning in progressive neuromuscular disorders. Generally, in this kind of disease, in a proactive management care plan, the role of the clinician is to monitor the progress of the disease and
From the Neuromuscular Clinic, Centre de réadaptation en déficience physique, Jonquière, (CG, JM); Research Centre on Aging, Sherbrooke Geriatric University Institute, Sherbrooke (JD); Faculty of Medicine, Université de Sherbrooke, Sherbrooke, (JD); Faculty of Medicine, Université de Montréal, Montréal (JM); Québec, Canada. ReCEIVED DeCEMBER 12, 2003. ACCEPTED INFINALFORM MAY 25, 2004.

Reprint requests to: Cynthia Gagnon, Centre de réadaptation en déficience physique de Jonquière, 2230 de l'Hôpital, C.P. 1200, Jonquière, Québec G7X 7X2, Canada 
to decide when to refer the individual to rehabilitation and social services. In the context of limited evaluation time in clinical settings, measurement instruments and methods have to be carefully chosen in order to get an accurate picture of the patient.

Among clinical evaluations, measurement of coordination is of particular interest in neuromuscular disorders with predominant ataxic features, such as Freidrich's ataxia. Coordination is defined as the capacity to execute a controlled movement with accuracy and rapidity. ${ }^{1}$ Its measure involves the appropriate activation of muscles with temporal and spatial components. ${ }^{2}$ Quantification of upper extremity coordination has been used as a diagnostic tool, to measure disease progression and to evaluate the impact of a given treatment. ${ }^{3,4}$ Desrosiers and collaborators ${ }^{5}$ have demonstrated moderate correlations between coordination and global upper extremity performance in an elderly population, which could be expected since coordination is a prerequisite of adequate upper extremity performance but not the only aspect to take into consideration. ${ }^{1}$

Among disorders with ataxic symptoms, autosomal recessive spastic ataxia of Charlevoix-Saguenay (ARSACS) (MIM 270550) is an early-onset familial ataxia with pyramidal, cerebellar and distal neuropathic involvement of variable intensity. ${ }^{6}$ It is an inherited spinocerebellar degeneration found predominantly in the population of the northeastern part of the province of Quebec, Canada. Autosomal recessive spastic ataxia of Charlevoix-Saguenay is characterized by developmental defects in the fiber myelination of the central and peripheral nervous systems, with progressive axonal degeneration of the corticospinal and spinocerebellar tracts and axonal neuropathy. There are about 300 patients living today in the region of Saguenay-Lac-St-Jean and Charlevoix with equal prevalence between genders. ${ }^{6,7}$ Richter and colleagues ${ }^{8}$ have located the gene responsible for ARSACS on chromosome 13 (13q11) and two ancestral haplotypes were identified.

Clinical manifestations start early (around 18 months) usually with gait ataxia and history of falling reported by the parents. The early signs of the disease are slight ataxia and spasticity, predominantly in the legs. The disease progression becomes most obvious in the late teens and early twenties and the mean age at which patients become wheelchair-bound is 41 years old.,

Although ARSACS mainly affects the lower limbs (incoordination, weakness and spasticity), upper extremity disabilities are also present and include incoordination, decreased dexterity and, for some patients, moderate to severe distal amyotrophy of the first dorsal interossei. ${ }^{6,9}$ Upper limb incoordination is a key characteristic of the assessment in this population.

Several methods have been used to quantify coordination. ${ }^{1,10-13}$ The traditional finger-nose test is a commonly used method and needs no specific apparatus. However, finger-nose tests are not standardized and several methods are used in clinical and research settings. For example, the finger-nose test can involve subjects alternately touching their nose and the evaluator's finger in different positions or touching their nose and fully extending their arm in front of them. ${ }^{11}$ In addition, the traditional fingernose test generates gross qualitative observations, which are not suited to the longitudinal observations needed to measure disease progression. Instrumental measures of coordination have also been developed but are rarely found in clinical practice as they take more time to administer. ${ }^{10,14}$ Moderate correlations between clinical and instrumental measures of coordination were demonstrated in people with brain damage and indicated a complementary role of the two measures. ${ }^{11}$

The traditional finger-nose test generally includes measures of time of execution, dysmetria and tremor. ${ }^{1,3}$ The evaluation of dysmetria and tremor has shown poor test-retest and interrater reliablity. ${ }^{15}$ The measure of time of execution, on the other hand, demonstrated excellent test-retest and interrater reliability. ${ }^{15}$ In order to increase reliability, Desrosiers and collaborators ${ }^{1}$ developed a protocol for a Standardized Finger-Nose Test (SFNT), and reference values for speed of execution are available for the older adult population (60 years and over). However, little is known about the validity of the test with a neuromuscular clientele with ataxic characteristics.

The validity of a test refers to its ability to measure the general and specific characteristics for which it was designed. ${ }^{16}$ Different types of validity of a test may be verified. ${ }^{16}$ Criterion validity is mainly studied by comparing a test to a gold standard measure. However, this benchmark measure is not always available. In such cases, construct validity is examined. This evaluates an instrument's ability to confirm a hypothesis or theoretical construct related to the variable measured. Several types of construct validity can be studied, including convergent and discriminant validity. Convergent validity refers to the relationship with another instrument, itself reliable and valid, that measures a similar concept whereas discriminant validity refers to the ability of an instrument to differentiate between groups on a selected variable. ${ }^{17}$

The objectives of this study were to explore 1) the convergent construct validity of the SFNTby correlating its score with upper extremity function tests that require coordination, functional independence and social participation, and 2) the discriminant construct validity of the SFNT by verifying its ability to differentiate between two age groups.

\section{MeThods}

\section{Participants}

A random sample of 24 participants with ARSACS, aged 18 and over were recruited from the Neuromuscular Clinic of the Centre de réadaptation en déficience physique in Jonquière, Québec, Canada. All the participants were homozygous for the mutation causing ARSACS on chromosome 13q11. For discriminant construct validity, the participants were stratified by age ( $<40$ years old and $\geq 40$ years old) into two groups, based on the clinical observation that involvement is much more severe after age $40 .^{9}$

All participants were free of any other form of motor or cognitive deficits that could affect upper extremity function. They signed an informed consent form approved by the Complexe Hospitalier de la Sagamie Ethics Committee.

\section{Data collection procedure}

Participants were evaluated by the same occupational therapist in two sessions. Upper extremity function, including coordination, was evaluated during the first session at the Clinic, while functional independence and social participation were evaluated during the second session at the participant's home. 


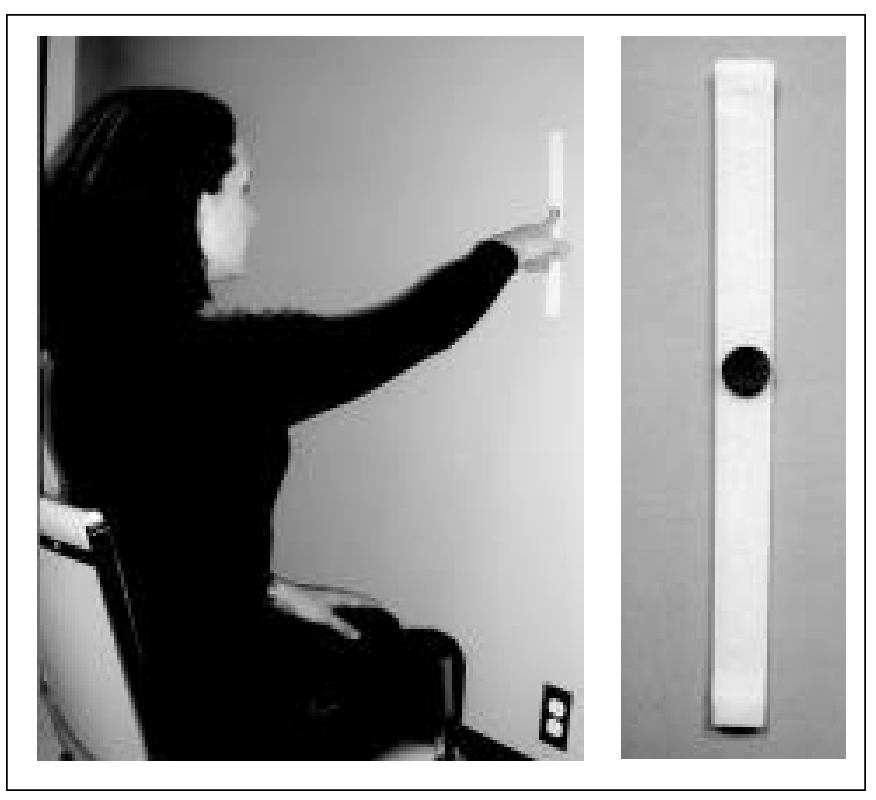

Figure: Position for the Standardized Finger-Nose Test

\section{Variables and measurement instruments}

\section{Upper extremity function}

Upper extremity motor coordination was estimated with the SFNT, ${ }^{1}$ a variant of the traditional Finger-Nose Test. Using the index finger, subjects must touch, alternately and as quickly as possible in a 20 -second period, the end of their nose and a horizontal target $45 \mathrm{~cm}$ away (Figure). The target is a red circle $2 \mathrm{~cm}$ in diameter that can be moved on a vertical axis according to the subject's height. The number of repetitions is recorded for one trial. If the target is not touched directly and accurately, subjects are instructed to move their finger to touch the target before returning to their nose. Accuracy of movement cannot therefore be sacrificed in order to increase speed of execution. Test-retest reliability (intraclass correlation coefficient: ICC) has been estimated at 0.97 for the right side and at 0.99 for the left, with interrater reliability of 0.92 and 0.91 respectively. ${ }^{15}$

Gross manual dexterity was estimated with the standardized procedures of the Box and Block Test. ${ }^{18}$ In this test, the subject has to move, one by one, the maximum number of blocks from one compartment of a box to another of equal size, within 60 seconds. One trial is done for each side and the number of blocks recorded. Test-retest reliability (ICC) has been estimated at 0.97 for the right side and at 0.96 for the left side with subjects with upper extremity impairments. ${ }^{19}$

The Purdue Pegboard was used to measure unilateral and bilateral fine finger dexterity. ${ }^{20}$ The Purdue Pegboard comprises four tasks where the subject has to place pins, washers and collars on a board within 30 or 60 seconds, depending on the task. According to recommendations, two trials are done for each task and the number of completed arrangements is recorded. ${ }^{21,22}$ Test-retest reliability has been estimated between 0.66 to 0.90 , depending on the task. ${ }^{21}$
Upper extremity strength was measured using three different measurement instruments. First, shoulder abductors, elbow flexors, wrist extensors and 1st dorsal interossei were evaluated with the Microfet-2 (Hoogan Health Industries) and belt-resisted method following Desrosiers' ${ }^{23}$ specifications for upper extremity evaluation. Test-retest reliability coefficients varied between 0.88 and 0.96 , depending on the muscle group. ${ }^{23}$ Second, grip strength was measured using the Jamar dynamometer (Asimow Engineering Co) following standardized procedures (mean of three measures). ${ }^{24}$ Test-retest reliability was estimated at 0.96 for the right hand and at 0.95 for the left. ${ }^{24,25}$ Finally, a pinch gauge (B\&L Engineering) was used to measure the strength of the 1 st dorsal interossei following Mathiowetz and colleagues' ${ }^{24}$ recommendations (mean of three measures). Test-retest reliability has been estimated at 0.83 for the right side and at 0.87 for the left. ${ }^{24}$

The TEMPA was used to measure global upper extremity performance. It consists of nine standardized tasks (five bilateral and four unilateral), representing daily activities. ${ }^{26}$ The speed of execution and functional rating of each task are recorded for one trial. The functional rating corresponds to the person's independence in performing each task and is measured on a 4point scale from 0 (the task is successfully completed without hesitation or difficulty) to -3 (the task is not completed). Intraclass correlation coefficients ranged from moderate to high (0.70-1.0) for test-retest reliability of speed of execution and functional rating. ${ }^{5}$

\section{Functional independence}

The Functional Independence Measure (FIM) was administered to evaluate functional independence. ${ }^{27}$ This scale includes 18 items which assess, on a seven-level scale, independence in basic daily activities in six domains: self-care, sphincter control, transfers, locomotion, communication and social cognition. Based on a meta-analysis, the test-retest reliability median is $0.95 .^{28}$ In this study, only items that require major use of the upper extremity were used: eating, grooming, bathing and upper extremity dressing, and this subscore was called FIM-upper extremity. The score varies from 4 to 28, with the latter indicating a higher level of independence. This subscore was developed specifically for this study in order to focus on activities related to upper extremity use. In the context of this study, this subscale appeared more valid than using the measure's entire motor subscore.

\section{Social participation}

Social participation is a conceptual domain of the new International Classification of Functioning and the Disability Creation Process. ${ }^{29,30}$ In this model, social participation is operationalized by the concept of life habits, which refers to "daily activities and social roles that ensure the survival and development of a person in society throughout his or her life". ${ }^{30}$ Social participation was evaluated using the short version of the Assessment of Life Habits (version 3.0) composed of 69 items. ${ }^{31}$ These items are grouped into 12 categories: nutrition, fitness, personal care, communication, housing, mobility, responsibility, interpersonal relationships, community life, education, employment and leisure. The first six categories refer to daily activities while the others are associated with social roles. The measure of each item is based on two specific elements: 1) 
degree of difficulty, and 2) type of assistance (technical assistance, physical arrangements, human help). The scale ranges from 0 to 9 where a score of 9 indicates complete independence without human or technical assistance (maximum level of social participation). Conversely, a score of 0 indicates that the activities or role cannot be accomplished because of tremendous difficulty or environmental factors. The reliability of the global score recently studied with older adults with physical disabilities is excellent (ICC and 95\% confidence intervals: 0.95 (0.91 to 0.98 ) for test-retest). ${ }^{32}$

\section{Statistical analysis}

The statistical analysis was performed using the SPSS 10.0 software package. ${ }^{33}$ Means and standard deviations for upper extremity function tests, functional independence and social participation scores are presented. For upper extremity function tests, a combined total score was computed in order to reduce the number of correlations by averaging the scores of the right and left upper extremities since no significant differences were found between the two performances. Spearman's correlation coefficient was used to estimate the convergent validity of the

Table: Scores of upper extremity functions, functional independence and social participation of 24 patients with ARSACS and their correlations with the SNFT

\begin{tabular}{|c|c|c|c|}
\hline & \multicolumn{3}{|c|}{$\begin{array}{c}\text { Standardized Finger-Nose Test } \\
[8.9 \text { (SD: } 4.2)] \\
1.5-16.5 \\
\end{array}$} \\
\hline & $\begin{array}{l}\text { Mean } \\
(\text { SD })\end{array}$ & $\begin{array}{l}\text { Spearman's } \\
\text { Rho }\end{array}$ & $p$ value \\
\hline \multicolumn{4}{|l|}{ Upperextremity function tests } \\
\hline Gross dexterity (BBT) & $32.2(11.8)$ & 0.82 & 0.01 \\
\hline Fine dexterity (PP) & $4.2(2.9)$ & 0.82 & 0.01 \\
\hline \multicolumn{4}{|l|}{$\begin{array}{l}\text { Upperextremity performance } \\
\text { (TEMPA) }\end{array}$} \\
\hline Functional rating (/39) & $13.4(8.5)$ & 0.79 & 0.01 \\
\hline Speed of execution (sec) & $290.4(216.2)$ & 0.74 & 0.01 \\
\hline \multicolumn{4}{|l|}{ Strength $(\mathbf{k g})$} \\
\hline Pinch strength (B\&L) & $5.7(1.9)$ & 0.56 & 0.01 \\
\hline Grip (Jamar) & $29.1(11.2)$ & 0.49 & 0.05 \\
\hline Shoulder abductors & $25.1(12.1)$ & 0.48 & 0.05 \\
\hline Elbow flexors & $39.4(14.4)$ & 0.19 & NS \\
\hline Wrist extensors & $32.3(12.4)$ & 0.38 & NS \\
\hline \multicolumn{4}{|l|}{ Functional independence } \\
\hline (FIM-UE) (/28) & $24.7(4.3)$ & 0.74 & 0.01 \\
\hline \multicolumn{4}{|l|}{ Social participation } \\
\hline$(\mathrm{LIFE}-\mathrm{H})(/ 9)$ & $7.6(1.0)$ & 0.78 & 0.01 \\
\hline
\end{tabular}

BBT: Box and Block Test; PP: Purdue Pegboard; TEMPA: Test Évaluant les Membres supérieurs des Personnes Âgées; FIM-UE: Functional Independence Measure-Upper Extremity; LIFE-H: Assessment of Life Habits
SFNT test with the other upper extremity tests, functional independence and social participation. Wilcoxon's signed rank test was used to demonstrate the discriminant construct validity of the SFNT. Significance for all the statistical analyses was fixed at the 0.05 level.

\section{RESUlts}

The distribution of gender ( $50 \%$ female) and age $(37.5 \%<40$ years old) is equivalent to that in the population with ARSACS. The Table shows means and standard deviations for each upper extremity function, functional independence and social participation as well as Spearman's correlation coefficients between these measures and coordination. The convergent validity of the SFNT was supported by moderate to strong correlations with the measures of dexterity (0.82), global upper extremity performance (0.74-0.79), upper extremity functional independence (0.74) and social participation (0.78). The moderate to low correlations found with measurements of muscle strength (0.19-0.56) also supported the validity of the test since minimal strength is a prerequisite for coordination.

The coordination score measured with the SFNT is significantly lower in patients over 40 years of age (6.7; SD: 3.4$)$ than in patients below $40(12.7 ; \mathrm{SD}: 2.2)(\mathrm{p}<0.001)$, supporting the discriminant validity of the SFNT.

\section{Discussion}

Coordination is known to affect several aspects of daily living such as the ability to execute basic activities of daily living, to work and to engage in recreational activities. ${ }^{34}$ Fast and simple quantitative tests of neurological function need to be developed and/or validated since neurological examination is an essential part of the neurologist's curriculum. ${ }^{35}$ The SFNTmeets these two criteria since it takes less than two minutes to administer and can easily be set up in any clinician's office as it requires only a few items. The objectives of this study were to explore the convergent and discriminant construct validity of the SFNT in a population with ataxic features. The convergent validity of the test was demonstrated by correlating the SFNT with other tests measuring variables that were expected to be associated. The strong correlations $(>0.80$ ) found between coordination and dexterity demonstrated their close relationship. By definition, dexterity requires coordination, sensitivity and prehension. ${ }^{36}$ It is known that sensitivity is usually intact in $\operatorname{ARSACS}^{6}$ and prehensions are possible. Therefore, the disturbance of coordination or ataxia in this disease seems to be the most important factor in the decrease in dexterity. These relationships support the use of the SFNT as an adequate measure of coordination and dexterity, that can be used with confidence in the clinical evaluation of this population.

The SFNT was also moderately correlated (rho: 0.48-0.56) with shoulder strength, grip strength and strength of the 1st interossei (pinch strength). The analysis of the movements executed during the SFNT provides an understanding of these relationships. First, the SFNT requires good stability of the shoulder as the subject has to stay at a precise height during the elbow extension and flexion movements. Secondly, sufficient upper limb strength is necessary in order to be able to execute rapid and precise movements. Therefore, the moderate 
correlations found between grip strength and coordination support the role of strength in the execution of precise movements.

Global upper extremity performance, upper extremity functional independence and social participation were highly correlated with SFNT (rho: 0.74-0.79), which demonstrated the important role coordination plays in everyday activities. These relationships suggest that incoordination may play a significant role in the decline of function observed in ARSACS and needs to be better defined. Correlations were stronger than those reported in Desrosiers'study with older adults, which could be explained by the greater variability of coordination in our population with cerebellar involvement. ${ }^{5}$ Indeed, statistics involving correlation can be influenced by the magnitude of variation within a specific population. Generally, a population with an ataxic disorder could be expected to demonstrate a greater variance in the score than the general population on a coordination test. Coordination was found to play a similar role in another study carried out with people with multiple sclerosis. In that study, the measure of coordination along with the measure of verbal intelligence and FIM admission score explained $56 \%$ of the variance in the patient's functional improvement (FIM discharge score) ${ }^{37}$ Therefore, the SFNT could possibly be a predictor of decline in functional independence and help clinicians refer people with increasing difficulty to rehabilitation and social services early in the process, without having to go through a sophisticated evaluation.

The discriminant construct validity of the SFNT was demonstrated as the scores were statistically lower for the older group, which was expected given the progressive nature of the disease and clinical findings. ${ }^{9}$ Indeed, despite the cross-sectional design of the study, the SFNT scores showed a progressive decrease with age. Upper limb motor coordination is known to decrease with age but the rate of progression is faster in ARSACS than in an older adult population (60 years of age and over). ${ }^{1}$ Therefore, the SFNT could generate more reliable and sensitive objective data on a longitudinal basis than the traditional subjective clinician's finger-nose test.

Finally, the reader should bear in mind that the study sample comprised only one form of ataxic syndrome. Therefore, any inferences regarding the usefulness of the SFNT in other forms of ataxic syndromes should be made with caution.

The convergent validity of the SFNT was demonstrated by its relationships with related upper extremity functions tests, functional independence and social participation. These correlations also suggest that the SFNTcould potentially be used as a measure of upper extremity function in a screening evaluation. Discriminant validity was demonstrated by the significant differences between the younger and older groups on the SFNT scores. The SFNT is a simple test that can be administered in any setting, requires no instrumentation and has been shown to be useful in other populations. In addition, the SFNT combines a standardized target with timing, which could help to reduce the interrater variability observed in other types of coordination tests and improve the longitudinal follow-up of population with ataxic features. The validation of the test should continue but its potential as a clinical tool for upper extremity function in a neuromuscular disorder with ataxic features was demonstrated.

\section{ACKNOWLEDGEMENTS}

The authors thank physiotherapist Louise Laroche and all the Neuromuscular Clinic staff of the Centre de réadaptation en déficience physique in Jonquière. We also thank all the study participants. This study was carried out with the financial support of the Réseau provincial de recherche en adaptation-réadaptation of the Fonds de la recherche en santé du Québec.

\section{REFERENCES}

1. Desrosiers J, Hebert R, Bravo G, Dutil E. Upper-extremity motor co-ordination of healthy elderly people. Age Ageing 1995; 24:108-112.

2. Bourbonnais D, Vanden Noven S, Pelletier R. Incoordination in patients with hemiparesis. Can J Public Health 1992;83:S58S63.

3. Notermans NC, van Dijk GW, van der Graaf Y, van Gijn J, Wokke $\mathrm{JH}$. Measuring ataxia: quantification based on the standard neurological examination. J Neurol Neurosurg Psychiatry 1994; 57:22-26.

4. Hooper J, Taylor R, Pentland B, Whittle IR. A prospective study of thalamic deep brain stimulation for the treatment of movement disorders in multiple sclerosis. Br J Neurosurg 2002; 16:102-109.

5. Desrosiers J, Hebert R, Bravo G, Dutil E. Upper extremity performance test for the elderly (TEMPA): normative data and correlates with sensorimotor parameters. Test d'Evaluation des Membres Superieurs de Personnes Agees. Arch Phys Med Rehabil 1995; 76:1125-1129.

6. Bouchard JP, Barbeau A, Bouchard R, Bouchard RW. Autosomal recessive spastic ataxia of Charlevoix-Saguenay. Can J Neurol Sci 1978; 5:61-69.

7. De Braekeleer M, Giasson F, Mathieu J, et al. Genetic epidemiology of autosomal recessive spastic ataxia of Charlevoix-Saguenay in northeastern Quebec. Genet Epidemiol 1993; 10:17-25.

8. Richter A, Rioux JD, Bouchard JP, et al. Location score and haplotype analyses of the locus for autosomal recessive spastic ataxia of Charlevoix-Saguenay, in chromosome region 13q11. Am J Hum Genet 1999; 64:768-775.

9. Bouchard JP. Recessive spastic ataxia of Charlevoix-Saguenay. In: Jong JMBVd, (Ed). Handbook of Clinical Neurology. Hereditary Neuropathies and Spinocerebellar Atrophies. Vol. 16 (60). Amsterdam: Elsevier Science Pub, 1991:451-459.

10. Verkerk PH, Schouten JP, Oosterhuis HJ. Measurement of the hand coordination. Clin Neurol Neurosurg 1990; 92:105-109.

11. Swaine BR, Sullivan SJ. Relation between clinical and instrumented measures of motor coordination in traumatically brain injured persons. Arch Phys Med Rehabil 1992; 73:55-59.

12. Erasmus LP, Sarno S, Albrecht H, et al. Measurement of ataxic symptoms with a graphic tablet: standard values in controls and validity in multiple sclerosis patients. J Neurosci Methods 2001; 108:25-37.

13. Legros B, Jacquy J, Manto MU. [Interobserver reliability of a new horizontal pointing manoeuvre: comparison with conventional tests]. Rev Neurol (Paris) 2000; 156:987-992.

14. Kondraske GV, Potvin AR, Tourtellotte WW, Syndulko K. A computer-based system for automated quantitation of neurologic function. IEEE Trans Biomed Eng 1984; 31:401-414.

15. Swaine BR, Sullivan SJ. Reliability of the scores for the finger-tonose test in adults with traumatic brain injury. Phys Ther 1993; 73:71-78.

16. Streiner D, Norman G. Health Measurement Scales: A Practical Guide to their Development and Use. New York: Oxford University Press, 1995.

17. Frytak J. Measurement. J Rehabil Outcomes Meas 2000; 4:15-31.

18. Mathiowetz V, Volland G, Kashman N, Weber K. Adult norms for the Box and Block Test of manual dexterity. Am J Occup Ther 1985; 39:386-391.

19. Desrosiers J, Bravo G, Hebert R, Dutil E, Mercier L. Validation of the Box and Block Test as a measure of dexterity of elderly people: reliability, validity, and norms studies. Arch Phys Med Rehabil 1994; 75:751-755. 
20. Tiffin J. Purdue Pegboard Examiner Manual. Chicago, IL: Science Research Associates, 1968.

21. Desrosiers J, Hebert R, Bravo G, Dutil E. The Purdue Pegboard Test: normative data for people aged 60 and over. Disabil Rehabil 1995; 17:217-224.

22. Reddon JR, Gill DM, Gauk SE, Maerz MD. Purdue Pegboard: testretest estimates. Percept Mot Skills 1988; 66:503-506.

23. Desrosiers J, Rochette A, Payette H, et al. Upper extremity isometric strength measurement using the belt-resisted method: reliability study with healthy elderly people. Can J Rehab 1998; 11:149155.

24. Mathiowetz V, Weber K, Volland G, Kashman N. Reliability and validity of grip and pinch strength evaluations. J Hand Surg [Am] 1984; 9:222-226.

25. Hamilton A, Balnave R, Adams R. Grip strength testing reliability. J Hand Ther 1994; 7:163-170.

26. Desrosiers J, Hébert R, Dutil É, Bravo G. Development and reliability of an upper extremity function test for the elderly: the TEMPA. Can J Occup Ther 1993; 60:9-16.

27. Data Management Service of the Uniform Data System of Medical Rehabilitation and the Center for Functional Assessment Research. Buffalo, 1991.

28. Ottenbacher KJ, Hsu Y, Granger CV, Fiedler RC. The reliability of the functional independence measure: a quantitative review. Arch Phys Med Rehabil 1996; 77:1226-1232.

29. WHO. International Classification of Functioning, Disability and Health: ICF. Geneva: WHO, 2001.

30. Fougeyrollas P, Cloutier R, Bergeron H, Côté J, St-Michel G. The Quebec Classification 'Disability Creation Process.' Quebec: International Network on the Disability Creation Process, 1999.

31. Fougeyrollas P, Noreau L, Dion SA, et al. Life Habits Scale (version 3.0). Lac-St-Charles, Québec, 1998.

32. Noreau L, Desrosiers J, Robichaud L, et al. Measuring social participation: reliability of the LIFE-H among older adults with disabilities. Disabil Rehabil 2004;26(6):346-352.

33. SPSS Advanced and Professional Statistics 10.0. Chicago: SPSS Incorporated, 2000.

34. Velickovic M, Gracies JM. Movement disorders. Keys to identifying and treating tremor. Geriatrics 2002; 57:32-36; quiz 39.

35. Lee RG. The neurologic examination - art or science? Can J Neurol Sci 2002; 29:305.

36. Poirier F. Dexterity as a valid measure of hand function: a pilot study. Occup Ther Health Care 1987; 4:69-83.

37. Langdon DW, Thompson AJ. Multiple sclerosis: a preliminary study of selected variables affecting rehabilitation outcome. Mult Scler 1999; 5:94-100. 